\title{
Surgical treatment of carcinoma of the oesophagus*
}

\author{
Raymond Hurt
}

That which is New at this time will one day be Ancient; as what today is Ancient was once New . . . it is not Length of Time which can give a value to Things; it is only their own Excellency.

Belloste: The Hospital Surgeon, 1701'

Cancer of the oesophagus was described in China over 2000 years ago as $Y e G e$, which means dysphagia and belching. "Those discovered to suffer from oesophageal cancer in the autumn," it was said, "will not live through the next summer." In the second century Galen described "fleshy growths" as a cause of obstruction of the oesophagus associated with cachexia and a fatal outcome. Only 50 years ago a considered and realistic assessment of this disease was that it was beyond hope and help.

This particular malignancy has proved to be one of the most difficult types of growth to treat successfully and, as ED Churchill wrote in $1960,^{2}$

surgeons have travelled a long road to bring their craft to its present position. The road can be measured by milestones of triumph and progress; also by tombstones of tragedy and prejudice. The journey cannot be described as a particularly sentimental one, but rather as a struggle in which stern realism has usually obscured any elements of romance. Only the words of those who have lighted the way remain to show the romance of surgery. They are the words of earnest men, the strength of whose convictions exceeded the techniques available for its expression. These men stand poles apart from today's "bright boys" who are so facile in wielding the techniques they have inherited.

The history of the development of resection techniques for this disease has been "the tale of men repeatedly losing to a stronger adversary yet persisting in the unequal struggle until the nature of the problems became apparent and the war was won." Resection was first carried out for growths in the cervical oesophagus, then for growths at the lower end of the oesophagus (by the abdominal route), and finally for growths in the thoracic oesophagus. The saga may be divided into three distinct eras:

1877-1912 -early procedures, in which no attempt was made to restore continuity between the pharynx and the stomach (except for carcinoma of the cervical oesophagus); 1913-38-later procedures, in which continuity was restored, usually at a subsequent operation, by a presternal tube of skin, stomach, or jejunum or an external rubber tube;
1938 onwards - the ideal procedure of excision and immediate restoration of continuity within the chest or neck to allow normal swallowing.

Very slow progress was made because of the inaccessibility of the oesophagus, both in the neck and in the thorax; the lack of a serous coat to the oesophagus, which made early anastomotic techniques hazardous; and the location of the oesophagus in an area where postoperative infection was especially dangerous and rapid in its spread.

\section{Cervical oesophagus}

In Vienna in 1870 Theodor Billroth (fig 1), that giant among surgeons who was also a capable pianist, violinist, composer, and music critic, as well as a personal friend of Brahms, started to investigate the possibility of resection of the cervical oesophagus in dogs, ${ }^{4}$ at a time when the Viennese School of Surgery was at its height. He was assisted by Czerny, who in 1877, as professor of surgery in Heidelberg, achieved the first successful resection of an oesophageal carcinoma. An annular stricture a short distance below the pharynx was treated by local excision and a feeding cervical oesophagostomy was provided, and the patient survived for 12 months. ${ }^{5}$

Two years later (1879) Billroth himself resected a more extensive carcinoma, together with the larynx and thyroid gland, and a feeding oesophageal tube was left in place. After four weeks the operation wound was "encouraged to close," with the hope that epithelialisation would produce a new oesophageal channel. Bougies were passed to maintain the lumen but, alas, two weeks later a bougie passed into the mediastinum and the patient died three days later from mediastinitis. ${ }^{6}$ With this technique nine resections by Billroth and other surgeons had been reported by 1885 , but only four patients survived (from three to 12 months). ${ }^{7}$

A considerable advance was made in 1886 by von Mikulicz (Cracow University, Poland), also a pupil of Billroth and also a musician. As a young man he had not been supported by his father, who wished him to study law; so as

*Modified and abridged from the chapter "Historical survey of surgical treatment" in: Hurt RL, ed. Management of oesophageal carcinoma. London: Springer, 1989. 
Figure 1 Theodore Billroth, 1829-94.

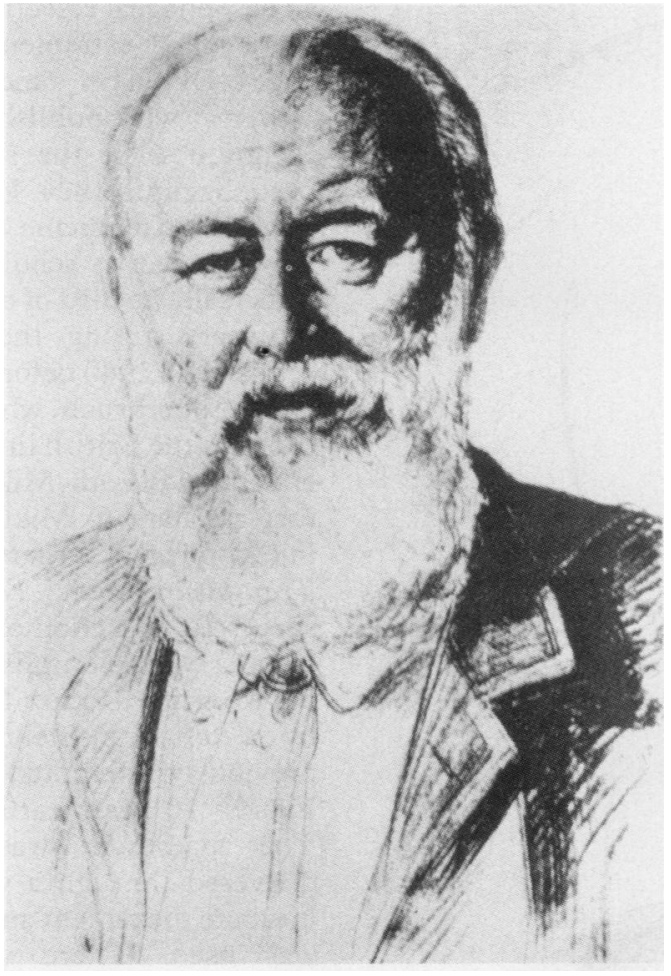

a medical student he lived on the income from piano lessons, which he gave before his classes began. $\mathrm{He}$ successfully reconstructed the cervical oesophagus by the use of skin flaps and the patient survived for 11 months. ${ }^{7}$ In 1891 von Hacker developed a technique to replace a segment of the cervical oesophagus in dogs by a horizontal bridge of skin and then attempted this, unsuccessfully, in a patient. ${ }^{8}$ Karl Garré of Switzerland reported three successful resections in 1898, the first two by a Mikulicz type of reconstruction and the third by a new technique using healthy laryngeal mucous membrane as a pedicle graft for consructing a new oesophagus. ${ }^{9}$ By the end of the nineteenth century Germany was clearly preeminent in the development of oesophageal resection, though Lotheisen commented, "Resection is often followed by severe oesophageal stricture.... This is particularly so if there is tension." $" 10$

In the United Kingdom progress was slow. In 1909 Evans (Westminster Hospital, London) resected a carcinoma of the larynx in a 63 year old patient. ${ }^{11}$ The upper oesophagus, brought out as a cervical oesophagostomy, was subsequently joined to a gastrostomy by a rubber tube, which the patient herself inserted before each meal. She was well 25 years later. ${ }^{12}$ Sir Arbuthnot Lane (Guy's Hospital) successfully resected a carcinoma of the upper oesophagus and back of the larynx in 1911, restoring continuity by the use of a skin flap. ${ }^{13}$ A similar type of operation was carried out on a 62 year old man by Wilfred Trotter in two stages in $1925,{ }^{14}$ with survival of the patient for 10 years, and Logan Turner (Edinburgh) resected a localised carcinoma from the back of the larynx and posterior pharyngeal wall in 1920 , leaving the larynx itself intact. ${ }^{15}$ The patient was subsequently fed through a tube inserted into a cervical oesophagostomy.

Little further progress was made until 1942, when Wookey (Toronto) reported four patients successfully treated by pharnygolaryngectomy with restoration of oesophageal continuity by skin flaps. ${ }^{16}$ In 1954 Raven (London) reported 23 consecutive operations using the same technique, from which eight patients survived 9-51 months. ${ }^{17}$ Despite these advances carcinoma at the upper end of the oesophagus, like postcricoid carcinoma, remained an extremely difficult surgical problem because of the proximity of the larynx. Growths at this level therefore have usually been treated by radiotherapy.

Recently, however, there has been renewed interest in surgical resection. Harrison (London, 1986) reported his results in 101 patients undergoing synchronous combined operation of pharyngolaryngectomy with radical neck dissection, and with restoration of continuity achieved by drawing up the stomach through the posterior mediastinum into the neck. The operative mortality was $9 \%$ and the five year survival rate $58 \% .{ }^{18}$

\section{Thoracic oesophagus}

The first successful resection of a carcinoma at the lower end of the thoracic oesophagus was carried out by Voelker (Heidelberg) by the abdominal route in 1908 through a left subcostal incision. The oesophagus was pulled down into the abdomen, the carcinoma (which must have been small) resected, and an oesophagogastric anastomosis made. Of the three patients operated on, only one survived; but at that time this was a remarkable achievement. ${ }^{19}$

The resection of most thoracic carcinomas, however, required entry through the thorax and there were two main approaches to this problem: (1) excision of the growth, with a cervical oesophagostomy and a feeding gastrostomy, followed later by the use of either an external rubber tube (Torek operation) or the construction of a presternal tube of skin, stomach, jejunum, or colon to restore continuity of the gullet; or (2) resection of the growth and an immediate anastomosis of the oesophagus to the mobilised stomach brought up into the chest. A third approach was by an operation without a formal thoracotomy.

\section{EXCISION OF THE GROWTH AND LATER} RECONSTRUCTION

The oesophagus could be exposed by an extrapleural or a transpleural route.

Extrapleural route The extrapleural route reduced the risk of pleural infection and Nassiloff (St Petersburg) must be given the credit for first suggesting, in 1888, this safer approach to the upper thoracic oesophagus "from the posterior part of the thorax outside the pleura by resecting four ribs." ${ }^{20} \mathrm{His}$ study of dissections in cadavers, repeated by Bryant ${ }^{21}$ in the United States in 1895 and by Potarca ${ }^{22}$ in Bucharest in 1898 (fig 2), was originally proposed for the removal of foreign bodies, and indeed Enderlen (Heidelberg) successfully removed a swallowed denture by this route in $1901 .^{23}$ 


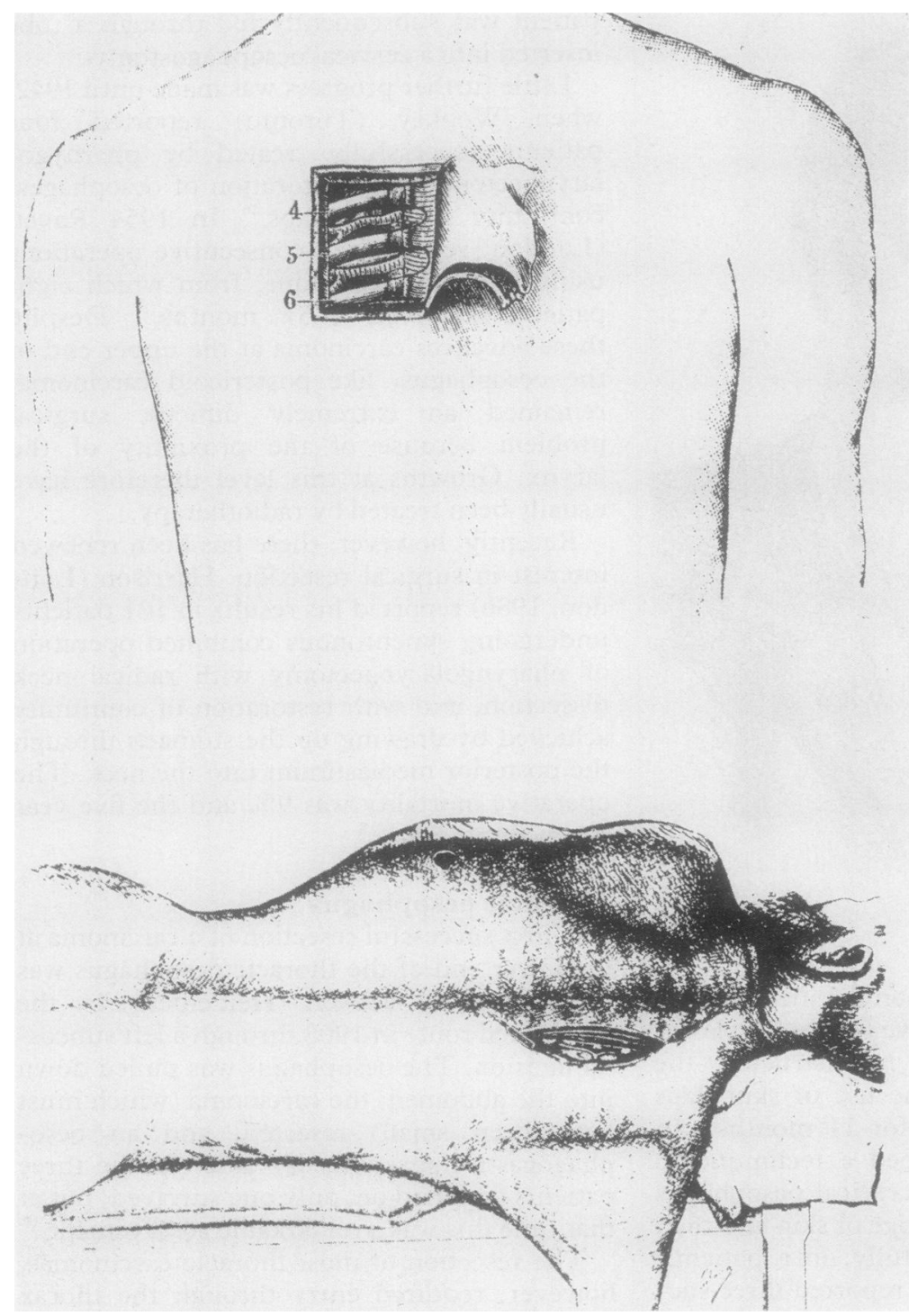

Figure 2 Bryant's (1895) approach to the posterior mediastinum (above) and Potarca's (1898) approach to the intrathoracic oesophagus (below).
In 1898 Ludwig Rehn (Germany) reported two cases of stricture of the oesophagus (one a carcinoma) in which the stricture was opened, a tube passed through, and the oesophagus sutured over the tube. ${ }^{24}$ Although both patients died, he was the first surgeon to approach the oesophagus directly through the chest by an extrapleural route and he paved the way for future attempts. Levy (1898) also considered that the extrapleural approach was preferable- "I must understandably refrain from suggesting that the deep seated cancer of the oesophagus in humans be removed in the same manner as I have torn out the oesophagus in dogs" (by a transpleural approach) ${ }^{25} \mathrm{~A}$ logical extension of this work was to use the extrapleural approach to resect carcinoma as it was thought that it would reduce the hazard of mediastinal and pleural infection; in fact most subsequent operations were by the transpleural route, as indeed was the first successful resection by Torek in 1913.

British workers prominent in this field were Lawrence Abel, ${ }^{26}$ who gave a Hunterian lecture in London in 1926 on experimental approaches to oesophageal resection (mainly by a posterior mediastinal extrapleural approach); Sir Heneage Ogilvie ${ }^{27}$; and $O^{\prime}$ Shaughnessy and Raven, ${ }^{28}$ who published a masterly paper on techniques for the surgical exposure of the oesophagus in 1934. Lawrence O'Shaughnessy qualified in medicine when only 21 , having won almost every scholarship open to him. Tragically he died of chest wounds at the age of 39 years during the British evacuation at Dunkirk in 1940 before, it is related, his former chief, Sauerbruch, who was given safe conduct through the British lines, could reach him. ${ }^{29}$ So ended the Bilroth-Mikulicz-Sauerbruch (a former assistant to Mikulicz)-British connection in oesophageal surgery.

Transpleural route: Torek operation The first successful resection of a mid oesophageal carcinoma was accomplished in 1913 on a 67 year old woman by Franz Torek (fig 3) of New York by a left transpleural approach, ${ }^{30}$ a route previously attempted by both Mikulicz $^{7}$ and Faure $^{31} 10$ years earlier but without success. The anaesthetic was simply $100 \mathrm{ml}$ ether delivered through a woven silk tube used to intubate the patient and no artificial ventilation was used. There were extensive pleural adhesions between the left lung and the parietal pleura and the lower end of the oesophagus was invaginated like an appendix stump. The upper end of the oesophagus with the carcinoma was brought out through a cervical incision, the carcinoma resected, and the remainder of the oesophagus tunnelled under the skin to make an oesophagostomy on the anterior chest wall at the second interspace. During the operation there was considerable concern at the need to divide the cardiac branches of the vagus nerve. During previous operations these nerves had

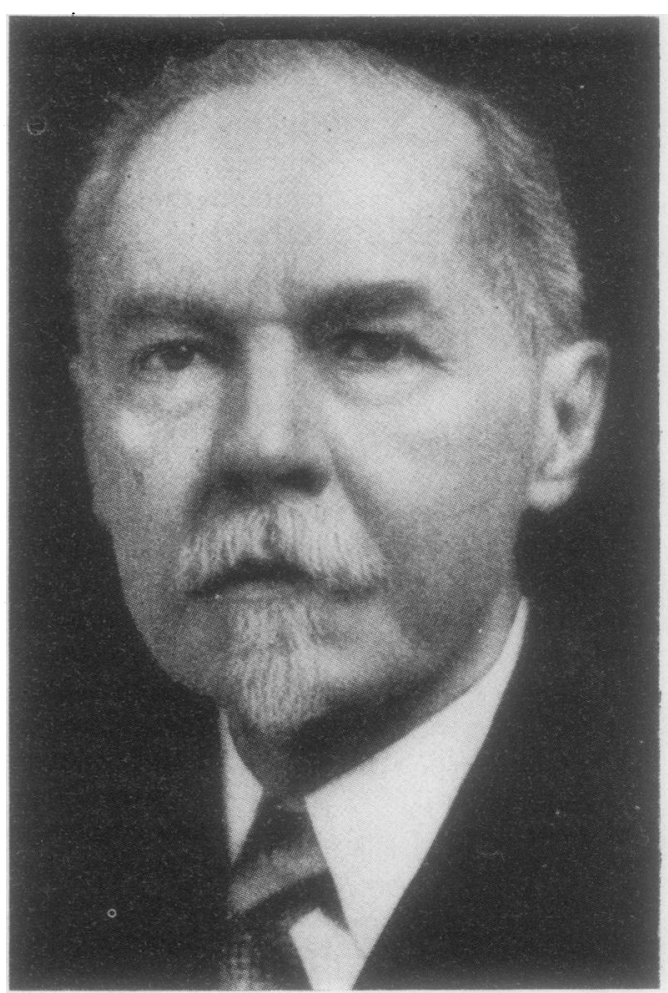

Figure 3 Franz Torek, 1861-1938. 
Figure 4 Photograph of Franz Torek's patient, who had the first resection of a carcinoma of the middle third of the oesophagus in 1913.

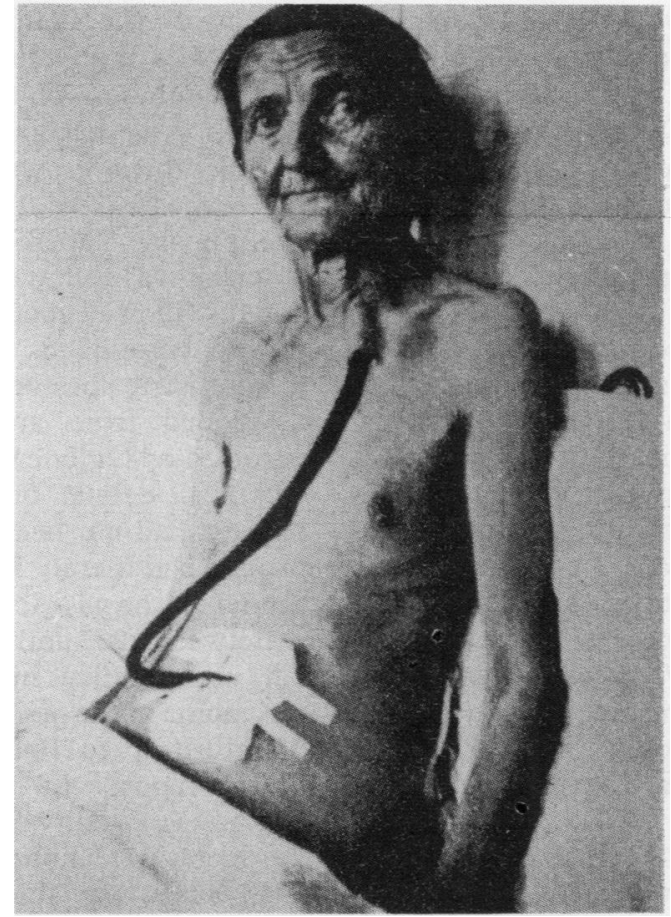

been anaesthetised by the local application of cocaine "to prevent the dreaded vagal collapse" due tovagal stimulation during mobilisation of the oesophagus and adjacent vagus nerves. No such collapse occurred, however. No pleural drain was used. At the end of the operation, which had lasted two hours 43 minutes, the patient was given a hot coffee enema with whisky and strychnine. Eight days later the cervical oesophagostomy and previously made gastrostomy were joined by a rubber tube (fig 4 ). She refused to have any plastic reconstruction of an antethoracic oesophagus and remained well for 13 years, dying from unrelated disease at the age of 80 years. The tumour was a squamous cell carcinoma. Torek was never able to repeat this successful operation, but 25 years later (1938) Garlock presented a report (with Torek in the audience) of three consecutive successful resections with the Torek technique. $^{32}$

Also in 1913, Zaaijer (Leiden) performed two successful staged transpleural resections of a carcinoma at the lower end of the oesophagus, using the Sauerbruch negative pressure chamber to aid anaesthesia. ${ }^{33} \mathrm{He}$ brought the upper end of the oesophagus on to the chest wall in the axilla (this had previously been mobilised by a 6th to 10th rib thoracoplasty to shorten the distance between the chest wall and oesophageal bed). Two years later (1915) Meyer reported that Ach (Munich) had performed a remarkable one stage Torek type operation in one hour 25 minutes. ${ }^{34} \mathrm{He}$ also noted that at that time only five patients had had a successful resection of a thoracic oesophageal carcinoma, "each one by a different plan." 34 This accurately described the "state of the art" of oesophageal resection at that time and showed the lack of uniformity of technique.

In the United Kingdom Tudor Edwards performed an extended Torek type of opera- tion in two hours in 1935 under a spinal anaesthetic with supplemental oxygen administered by a face mask. ${ }^{35}$ Further successful Torek operations were reported from 1936 to 1943 by Muir, ${ }^{36}$ Allison, ${ }^{37}$ Franklin, ${ }^{38}$ and Brock $^{39}$ in the United Kingdom and in 1936 by King $^{40}$ in Melbourne. In 1941 Oschner and DeBakey ${ }^{41}$ summarised the outcome, reporting that only 17 of 58 patients undergoing a Torek resection had survived, an operative mortality of $71 \%$.

\section{RESECTION AND IMMEDIATE ANASTOMOSIS}

Resection and immediate anastomosis proved to be an even greater challenge and many years passed before surgery was successful. Research was directed to methods of oesophageal reconstruction by either mobilisation of the stomach or the use of jejunum, colon, or skin.

Mobilisation of stomach Animal research by Bloch $^{42}$ in 1881, Biondi, ${ }^{43}$ in 1895, and Levy ${ }^{25}$ in 1898 showed that the oesophagus could be successfully anastomosed to the stomach and that the stomach could be used to replace the thoracic oesophagus.

In 1903 Gossett $^{44}$ (Paris) and in 1905 Sauerbruch $^{45}$ (Germany) carried out further animal experiments and cadavre dissections ("recherche cadaverique" as Gossett described this latter work). Carl Beck (a German emigré who became Professor of surgery in New York) must be given credit for first showing in animal experiments (1905) that the greater curvature of the stomach could be made into a tube long enough to reach high in the chest ${ }^{46}$ - a great advance in operative technique. Its use as a human presternal conduit was reported by Jianu (Hungary) in 1914 for benign stricture. ${ }^{47}$ In 1913 Willy Meyer, another German immigrant in New York, used the technique to bypass an inoperable carcinoma and suggested that this part of the stomach should be used to replace the lower oesophagus after resection. ${ }^{48}$ Elated by this success, he wrote that "this appears to have advanced by another great step the surgery of the oesophagus, which is now making headway by leaps and bounds."

Use of jejunum, colon, or skin In 1907 Roux (Lausanne) used a loop of jejunum as the lower part of a presternal conduit, the upper part being made from a skin tube. ${ }^{49}$ The operation was originally devised for benign stricture but it was subsequently used for carcinoma by Yudin (Russia), who reported its use in 200300 cases in $1944^{5051}$ and by Rienhoff ${ }^{52}$ in 1946 at Johns Hopkins Hospital, Baltimore. The technique was associated with a prohibitively high postoperative morbidity and mortality rate, however, until it was further developed by Allison (Leeds and Oxford). ${ }^{53}$

In 1911 Kelling (Dresden), after finding the mesentery of the jejunum to be too short, used the transverse colon to replace the oesophagus for the first time. This staged operation was almost successful..$^{54}$ Since 1945 ascending, transverse, and descending segments of colon, with preservation of their blood supply, have been used for oesophageal replacement, Belsey (Bristol) being the foremost advocate of this technique in the United Kingdom. ${ }^{55}$ 
Successful transpleural resection The first successful transpleural resection of the oesophagus with immediate restoration of continuity was carried out by Dobromysslov on a dog (Moscow) in $1901 ; 3-4 \mathrm{~cm}$ of oesphagus were resected and a direct end to end anastomosis was made. ${ }^{56}$ Resections in cadavers were also performed but no reports of this work were published.

Continued attempts to improve and simplify the operative technique met with little success until the work of Oshawa (Imperial University, Kyoto) was reported in $1933,{ }^{57}$ though it received no publicity in the West. He performed the first successful transthoracic oesophagectomy and primary oesophagogastric anastomosis for oesophageal carcinoma, and had regularly used since 1925 "free thoracotomy" without positive pressure ventilation for anaesthesia, which in some cases had been by the use of procaine only. Nineteen resections were reported, from which eight patients survived.

The importance of postoperative underwater seal drainage was not universally accepted at this time and it was not used in any of Oshawa's cases. As late as 1939 there was also considerable controversy about whether the diaphragm should be paralysed by phrenic crush at operation "during the time of healing of the anastomosis" "58; even in 1948 Garlock advised that the phrenic nerve should be crushed "to put the left leaf of the diaphragm at rest." ${ }^{59}$ Naturally, as is now recognised, this encouraged postoperative lung complications, a major cause of postoperative death.

In 1937 Nissen (University of Basle) reported a successful oesophageal resection with immediate oesophagogastric anastomosis, albeit for benign stricture. ${ }^{60}$ In the following year Marshall ${ }^{61}$ (Boston) and Adams and Phemister $^{62}$ (Chicago) separately reported successful transpleural resections of growths in the lower third of the oesophagus by a primary oesophagogastric anastomosis. Adams and Phemister are generally credited with priority but in fact this honour should go to Marshall, who carried out the resection in July 1937, six months before Adams and Phemister. Until this time only 30 successful Torek resections (by 13 different surgeons) had been reported in the United States, and only Torek's first patient had survived for more than five years. ${ }^{62}$ Torek's later patients succumbed soon after operation from mediastinal or less commonly pulmonary infection, as did those of most other surgeons using the same technique.

The first successful transpleural resection of a carcinoma of the lower third of the oesophagus with immediate restoration of oesophageal continuity in the United Kingdom was carried out by Vernon Thompson (London Hospital) in $1941 .^{63}$ This achievement was repeated in 1943 by Oswald Tubbs (St Bartholomew's Hospital) ${ }^{64}$ and G H Steel (Guildford), ${ }^{65}$ in 1944 by Ivor Lewis, ${ }^{66}$ and in 1945 by Dickson Wright ${ }^{67}$ (St Mary's Hospital).

Ivor Lewis (fig 5) (North Middlesex Hospital) presented his work on the right sided two phase approach for carcinoma of the middle third of the oesophagus in 1946. This introduces more difficult technical problems than carcinoma of the lower third-and this operation has become a standard procedure for middle third growths. ${ }^{66}$ Previous resections had usually been through the left chest. A preliminary laparotomy to mobilise the stomach was followed by a right thoracotomy and this allowed good access to the middle third of the oesophagus for an immediate oesophagogastric anastomosis. The procedure was developed from an unsuccessful operation reported by Ogilvie in 1938 at a time when the technical details of oesophagogastric anastomosis had not been perfected and the oesophagus had merely been intussuscepted into a tunnel on the gastric wall over a rubber tube. ${ }^{27}$

Between 1937 and 1948 there was a dramatic fall in operative mortality for resection of carcinoma of the oesophagus. In a review of the literature up to 1940 Oschner and DeBakey found reports of 191 resections with an operative mortality of $59-91 \%,{ }^{41}$ depending on the operative technique used (average $72 \%$ ); by 1948 Sweet was able to report a mortality of only $16.5 \%$ in a series of 181 resections. ${ }^{68}$

OESOPHAGECTOMY WITHOUT A FORMAL THORACOTOMY

Wolfgang Denk (Vienna) in 1913 described a "pull through" operation performed in cadavers in which he removed the oesophagus without any opening of the chest. ${ }^{69}$ A cervical oesophagostomy and a gastrostomy would be joined later by an antethoracic skin tube. Before 1941, however, the procedure was associated with a prohibitively high operative mortality and only three patients of the 32 reported survived surgery. ${ }^{41}$ Denk himself did not have any success but the procedure, which avoided the considerable risk at that time of

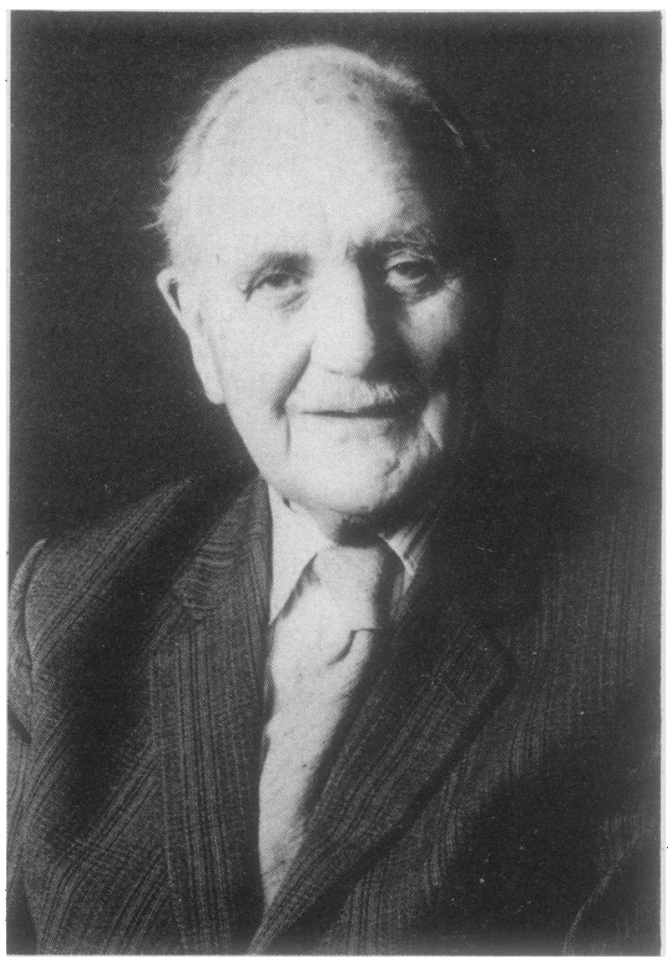

Figure 5 Ivor Lewis, 1895-1982. 
Figure 6 George Grey Turner, 1877-1951.

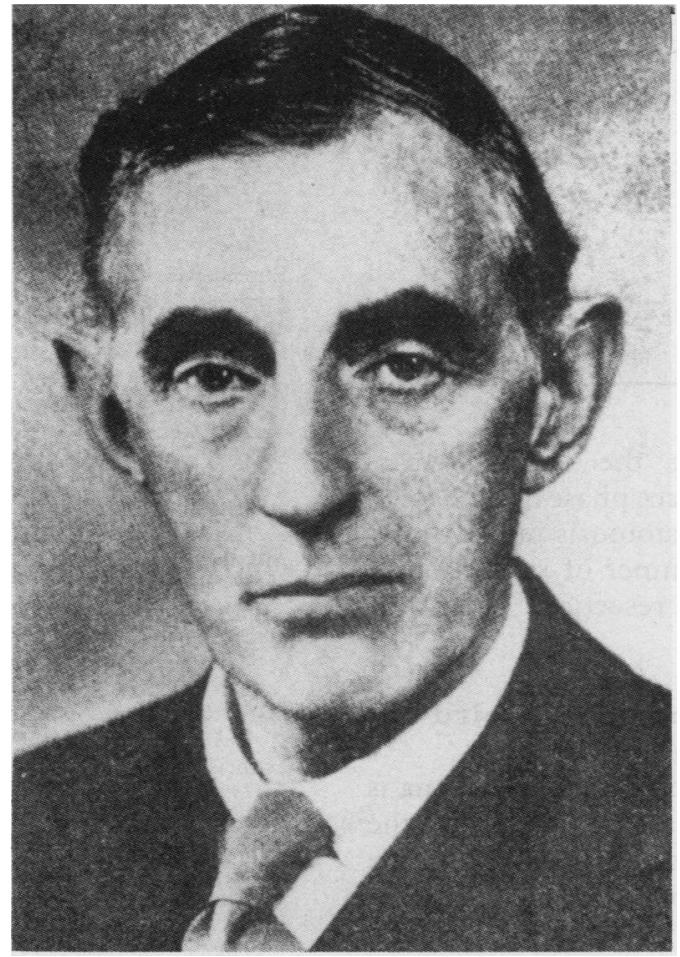

opening the chest, was later developed with considerable success by Grey Turner (fig 6) (in Newcastle upon Tyne and later at Hammersmith Hospital). In fact, Grey Turner carried out the first successful Denk type operation. His comment in 1931 that "surgery for carcinoma of the oesophagus has usually been considered the most unsatisfactory subject in the whole realm of surgery" epitomised surgical opinion at that time.

The problems encountered in the early days are well described in respect of his first operation in 1927. While the oesophagus was being mobilised from below "it was necessary to introduce the whole hand into the posterior mediastinum and to practise the manoeuvres of the obstetrician separating a retained placenta." The withdrawal of the oesophagus

was followed by a gush of blood but this soon stopped. As a precaution a large pack of gauze was temporarily thrust into the posterior mediastinum. The removal of the gauze pack disclosed an enormous yawning cavern, in and out of which air rushed with a terrifying and disconcerting noise. Fortunately all bleeding appeared to have ceased. It was not possible to draw together what had been the oesophageal aperture but it was effectively closed by applying the left lobe of the liver over it like the lid of a box, fixing it there by a stout suture. $^{70}$

The operation was completed in two hours, and was carried out without the benefits of modern thoracic anaesthesia, positive pressure ventilation (hence the air "rushing in and out"), readily available blood transfusion, or a proper understanding of the use of underwater seal drainage tubes after thoracotomy; this patient died from infection one week later. Grey Turner's first successful operation was on a 58 year old north of England miner, who had a mid oesophageal carcinoma in 1933. Oesophageal continuity was restored two months later by a presternal channel formed by a skin tube above and a jejunal loop below. ${ }^{71}$ His last successful operation, on a patient who survived for 14 years, was in $1945 .{ }^{12} \mathrm{His}$ overall operability rate was $44 \%$ and operative mortality rate $40 \%$; he had three long term successes from the 25 cases reported by Ogilvie in his Grey Turner lecture in 1959. ${ }^{12}$ Grey Turner's "pull through" technique was not attempted by many surgeons in either the United Kingdom or the United States; at that time a transpleural approach with the creation of a presternal oesophagus was the preferred technique. ${ }^{3772}$

\section{Two milestones-1913 and 1938}

The years 1913 and 1938 stand out as two milestones in the history of surgery for carcinoma of the oesophagus. 1913 was the year of the pioneering operations of Denk ("pull through" operation in cadavers), ${ }^{69}$ Meyer (the greater curvature of the stomach as a presternal conduit) ${ }^{48}$ Torek (first resection of a carcinoma in the middle third) ${ }^{30}$ and Zaaijer (two successful staged transpleural resections of carcinomas in the lower third). ${ }^{33} 1938$ was the year of the successful achievement in the Western world of primary transpleural oesophageal resection ${ }^{6162}$ and of Garlock's three consecutive successful Torek operations. ${ }^{32}$ Indeed, in 1938 oesophageal surgery emerged from the wilderness and became an established and satisfactory procedure. This was after "decades spent in trying to circumvent rather than face the dangers. $" 66$

\section{The modern era}

The modern era started immediately after the second world war, in 1945, by which time anaesthetic and anastomotic techniques, control of infection, and postoperative management had all improved to such an extent that primary resection and anastomosis could be carried out with an acceptable morbidity and mortality rate. By 1954 Garlock $^{72}$ was able to report 75 resections with an operative mortality of $33 \%$ and Sweet $^{73} 287$ resections with an operative mortality of $18 \%$.

In Japan, where the incidence of carcinoma of the oesophagus is very high, Nakayama (Oshawa's successor at Chiba University Hospital) gained enormous experience and in 1959 reported 953 resections, with an overall operative mortality rate of only $5 \cdot 8 \%{ }^{74}$ The oesophagogastric anastomosis had usually been carried out anterior to the sternum and this accounted for the very low mortality; when an intrathoracic anastomosis was carried out the mortality was $15 \%$.

During the last 20 years the Denk-Grey Turner "pull through" operation has been reintroduced by Orringer ${ }^{75}$ in the United States and by $\mathrm{Kirk}^{76}$ in the United Kingdom, often combined with a partial or complete median sternotomy. It is, however, considered by many to be essentially a palliative procedure for the relief of dysphagia. ${ }^{76}$ Orringer, on the other hand, claimed a mean five year survival rate of $22 \%$ in 130 patients, a figure similar to that achieved with more radical transthoracic resections. 
Surgical results of resection for lower and middle third oesophageal carcinoma

\begin{tabular}{|c|c|c|c|c|}
\hline Reference & $\begin{array}{l}\text { No of } \\
\text { cases }\end{array}$ & $\begin{array}{l}\text { Mortality } \\
(\%)\end{array}$ & $\begin{array}{l}\text { Two year } \\
\text { survival } \\
(\%)\end{array}$ & $\begin{array}{l}\text { Five year } \\
\text { survival } \\
(\%)\end{array}$ \\
\hline Couraud et al (1988) & 390 & $7 \cdot 6$ & 34 & 21 \\
\hline Dark et al (1981) & 449 & $7 \cdot 6$ & - & 18 \\
\hline Griffith and Davis (1980) & 211 & $11 \cdot 4$ & - & 15 \\
\hline Jackson et al (1979) & 216 & $18 \cdot 0$ & 25 & 14 \\
\hline Lea (1989) & 205 & 5 & - & 15 \\
\hline McKeown (1979) & 392 & $12 \cdot 2$ & - & - \\
\hline Orringer (1988) & 130 & 6 & 34 & 22 \\
\hline
\end{tabular}

Developments during the last 25 years include the McKeown three phase oesophagectomy operation with anastomosis in the neck ${ }^{77}$ and the advocacy by Skinner of radical oesophagectomy with en bloc resection. ${ }^{78}$

\section{Resection for lower and middle third oesophageal carcinoma today}

The management of oesophageal carcinoma is still very controversial and attitudes to the disease range from the pessimistic view that it is rarely cured to the more optimistic and realistic view that there is now some hope for some patients. Surgery provides a higher cure rate for intrathoracic growths than does radiotherapy ${ }^{79}$ but there is no unanimity of opinion about the preferred technique for resection.

The place of transhiatal oesophagectomy with no opening of the chest, an operation described by Belsey in 1978 as an expedition into the Dark Ages, ${ }^{80}$ is at present sub judice, and will remain so until the Orringer-Skinner controversy about oesophagectomy without formal thoracotomy versus radical en bloc resection of the oesophagus has been settled. The arguments for and against these operations are well documented in a leading article by Wong. ${ }^{81}$

The five year survival rate after resection for oesophageal carcinoma is still poor, though not as poor as was reported in a widely quoted article by Earlam and Cunha-Melo ${ }^{82}$ in 1980. In this collective review a mean operative mortality of $29 \%$ and a mean five year survival rate of $4 \%$ were quoted. These figures are grossly misleading, for they include series (15 out of 122) published before 1961, and those operations would therefore have been carried out up to 40 years ago. Furthermore, at least 21 authors had reported from their experience of fewer than 30 resections. It has now been shown that mortality rate is directly related to the number of operations carried out in a particular unit and that the operative mortality is unacceptably high in surgical units in which only a few resections are performed and in which experience of postoperative thoracic care is minimal. ${ }^{83}$

An operative mortality rate of $5-11 \%$ and a five year survival rate of $14-22 \%$ is the standard to be expected in 1991 in the Western world (table)..$^{754-89}$ The remarkably low mortality of $1.4 \%$ achieved by Akiyama has not been attained outside Japan, perhaps because "patients in the Orient are usually thin and present less technical difficulty than do patients with oesophageal cancer in the Occident" and also because of their extensive experience of this disease. ${ }^{90}$

1 Belloste. In: The hospital surgeon. London: Sprint, 1706. Quoted by Hochberg.

2 Churchill ED. In: Foreword to Hochberg LA. Thoracic surgery before the 20th century. New York: Vantage Press, 1960

3 Elmslie RG. Perspectives in the development of oesophageal surgery. In: Jamieson GG, ed. Surgery of the oesophagus. London: Churchill-Livingstone, 1988:3-8.

4 Billroth CAT. Uber die resektion des oesophagus. Arch Klin Chir 1871;13:65-9.

5 Czerny V. Neue Operationen; resektion des oesophagus. Zentr Chir 1877;4:433-4.

6 Billroth CAT. Totalextirpation des Ganzenoesophagus vom Pharynx bis zum Sternum; ein Totalextirpation des Ganzenlarynx mit des ganzen Schilddruse. Verhandl Deut Ges Chir 1879;8:7-9.

7 Mikulicz J von. Ein Fall von Resektion des Carcinomatosen Oesophagus mit plastichen Ersatz des exeidirten Stuckes. Prag Med Wochenschr 1886;11:93-4.

8 Hacker von. Uber Resektion und Plastik am Kebsabschnit der Spieserohre, inbesondere beim Carcinom. Arch Klin Chir 1908;87:257-323.

9 Garré K. Uber Oesophagusresektion und Oesophagoplastik. Arch Klin Chir 1898;57:719-22.

10 Lotheissen. In: von Bergman E, von Bruns P, Mikulicz J. Handbuch der Praktischen Chirurgie. Stuttgart: Enke, 1899.

11 Evans A. A rubber oesophagus. Br J Surg 1932;20:388-92.

12 Ogilvie WH. The surgery of the oesophagus. Br J Surg 1960;47:457-66.

13 Lane WA. Excision of a cancerous segment of the oesophagus: restoration of the oesophagus by means of a skin flap. Br Med J 1911; i:16-7.

14 Trotter W. [Reported by Pilcher R.] In: Carcinoma of the cervical oesophagus. Lancet 1937; i:73-6.

15 Turner L. Carcinoma of the post-cricoid region of the upper end of the oesophagus. Proc $R$ Soc Med (Section of Laryngology) 1920;13:199-202.

16 Wookey H. Surgical treatment of carcinoma of the pharynx and upper esophagus. Surg Gynecol Obstet 1942;75: 499-506.

17 Raven RW. Cancer of the oesophagus. Chir Thorac 1954; 7:3-23

18 Harrison DFN, Thomson AE. Pharyngolaryngoesophagectomy with pharyngogastric anastomosis for cancer of the hypopharynx: review of 101 operations. Head Neck Surg 1988;8:418-28.

19 Voelcker. Uber Extirpation der Cardia wegen Carcinoms. Verh Dtsch Ges Chir 1908;37:126-9.

20 Nassiloff II. Oesophagotomia et resectio oesophagi endothoracica. Vrach St Peterberg 1888;9:481-2.

21 Bryant JD. The surgical technique of entry to the posterior mediastinum. Trans Am Surg Ass 1895;13:443-59.

22 Potarca J. Du mediastinum posterieur et en particular trajet des plèvres mediastinales posterieures. Presse Méd 1898; 2:296-300. [Based on thesis, University of Bucharest, 18931.

23 Enderlen. Ein Beitrag zur Chirurgie des hinteren Mediastinum. Deut Zeitschr Chir 1901;61:441-95.

24 Rehn L. Operationen an dem brustabschnitt der speiserohre. Verh Dtsch Ges Chir 1898;21:448-70.

25 Levy W. Versuche über die Resektion der Speiserohre. Arch Klin Chir 1898;56:839-92.

26 Abel AL. Treatment of carcinoma of the oesophagus. $\mathrm{Br} J$ Surg 1926;14:131-59.

27 Ogilvie WH. Intrathoracic reconstruction of lower oesophagus. Br J Surg 1938;26:10-22.

28 O'Shaughnessy L, Raven RW. Surgical exposure of the oesophagus. Br J Surg 1934;22:365-77.

29 Monk I. Cited by Elmslie RG. Perspectives in the development of oesophageal surgery. In: Jamieson GG ed. Surgery of the oesophagus. London: Churchill-LivingSurgery of the
stone, 1988:3-8.

30 Torek $F$. The first successful case of resection of the thoracic portion of the oesophagus for carcinoma. Surg Gynecol Obstet 1913;16:614-7.

31 Fauré JL. Cancer de la portion thoracique de l'oesophage. Extirpation du neoplasme par la voie mediastinin posterior droite. Combinee a une incision cervicale. Bull Mem Soc Chir 1903;29:122-34.

32 Garlock JH. The surgical treatment of the thoracic esophagus. Surg Gynecol Obstet 1938;66:534-48.

33 Zaaijer JH. Erfolgreiche transpleurale Resektion eines Cardia-carcinoms. Beitr Klin Chir 1913;83:419.

34 Meyer W. Resection of cardia for carcinoma. Ann Surg 1915;62:693-709.

35 Edwards AT. Transpleural removal of total oesophagus. Proc R Soc Med 1935;29:188.

36 Muir EG. Resection of the lower oesophagus and cardia. Lancet 1936;ii: 75.

37 Allison PR. Report of four cases of oesophageal carcinoma treated by excision. Br J Surg 1943;30:132-41.

38 Franklin RH. Two cases of successful removal of the 
thoracic oesophagus for carcinoma. $\mathrm{Br} \quad J \quad$ Surg 1942;30:141-6.

39 Brock RC. Report of clinical meeting. Proc $R$ Soc Med 1943;37:38.

40 King ESJ. Oesophagectomy for carcinoma of the thoracic oesophagus. Br J Surg 1936;23:521-9.

41 Oschner A, DeBakey M. Surgical aspects of carcinoma of the esophagus. J Thorac Surg 1941;10:401-45.

42 Bloch MH. Experimentelles zur Lungenresektion. Dtsch Med Wochenschr 1881;7:634.

43 Biondi D. Experimental intrathoracic oesophago-gastrostomy. Policlinico (Suppl) 1895:964.

44 Gossett A. De l'oesophago-gastrostomie transdiaphragmatique. Rev Chir 1903;28:694-707.

45 Sauerbruch F. Experimentelle Beitrage zur Oesophaguschirurgie. Verh Disch Ges Chir 1905;34:140-9.

46 Beck C. Demonstration of specimens illustrating a method of formation of a pre-thoracic oesophagus. Illinois Medical Journal 1905;7:463.

47 Jianu A. Uber oesophagoplastik. Dtsch Chir 1914;131: $397-403$.

48 Meyer W. Oesophagoplasty. Ann Surg 1913;58:289-95.

49 Roux C. L'Oesophago-jejuno-gastrome, nouvelle operation pour retrecissement infrachisable de l'oesophage. Semaine Méd 1907:27:37.

50 Crafoord C. Discussion of paper by Harrison. J Thorac Surg 1949;18:325.

51 Yudin SS. The surgical construction of 80 cases of artificial esophagus. Surg Gynecol Obstet 1944;78:561-83.

52 Rienhoff WF. Intrathoracic oesophagojejunostomy for lesions of the upper third of the oesophagus. South Med J 1946;39:928-40.

53 Allison PR, Da Silva LT. The Roux loop. Br J Surg 1953;41:173-80.

54 Kelling. Oesophagoplastik mit hilfe des querkolon. Z $\mathrm{bl} \mathrm{Chir}$ 1911;38:1209-12.

55 Belsey RHR. Reconstruction of the oesophagus with left colon. J Thorac Cardiothorac Surg 1965;49:33-55.

56 Dobromysslov WD. Ein Fall von transpleuraler Osophagotomie im Brustabschnitte. Zbl Chir 1901;1:18.

57 Oshawa T. The surgery of the oesophagus. Arch Jap Chir 1933;10:604-95. [Quoted by Bird. ${ }^{38}$ ]

58 Bird CE. Recent advances in surgery of the esophagus. Surgery 1939;6:772-801.

59 Garlock JH. Progress in the surgical treatment of carcinoma of the esophagus and upper stomach. Surgery 1948;23 906-11.

60 Nissen $R$. Die transpleurale resektion der kardia. Dtsch Zeitschr Chir 1937;249:311-6.

61 Marshall SF. Carcinoma of the esophagus: successful resection of lower end of oesophagus with re-establishment of esophageal gastric continuity. Surg Clin North Am 1938; 18:643-8.

62 Adams WE, Phemister DB. Carcinoma of lower thoracic esophagus. J Thorac Surg 1938;7:621-32.

63 Thompson VC. Carcinoma of the oesophagus: resection and oesophago-gastrostomy. Br J Surg 1945;32:377-80.

64 Tubbs OS. Report, clinical section of the Royal Society of Medicine. Proc $R$ Soc Med 1943;37:39.

65 Steel GH. Carcinoma of the oesophagus. Lancet 1943;ii: 797-8.

66 Lewis I. Surgical treatment of carcinoma of the oesophagus.
Br J Surg 1946;34:18-31.

67 Wright D. Report, clinical section of the Royal Society of Medicine. Proc R Soc Med 1945;38:131.

68 Sweet RH. Treatment of carcinoma of the esophagus and cardiac end of stomach by surgical extirpation. Surgery 1948;23:952-75.

69 Denk W. Zur Radikaloperation des Oesophaguskarzinoms. Zentralbl Chir 1913;40:1065-8.

70 Turner GG. Some experiences in the surgery of the esophagus. N Engl J Med 1931;205:657-74.

71 Turner GG. Excision of thoracic oesophagus for carcinoma. Lancet 1933;ii:1315-6.

72 Garlock JH, Klein S. Surgical treatment of carcinoma of esophagus and cardia. Ann Surg 1954;139:19-34.

73 Sweet RH. Late results of surgical treatment of carcinoma of the esophagus. JAM $A$ 1954;155:422-5.

74 Nakayama K. Statistical review of 5 year survivals after surgery for carcinoma of esophagus and cardiac portion of stomach. Surgery 1959;45:883-9.

75 Orringer MB. Transhiatal esophagectomy without thoracotomy for esophageal carcinoma. In: Delarue NC, Wilkins EW, Wong J, eds. International trends in general Wilkins EW, Wong J, eds. International trends in general

76 Kirk RM. Transhiatal oesophagectomy without formal thoracotomy. In: Hurt RL. Management of oesophageal carcinoma. London: Springer, 1989:187-201.

77 Mckeown KC. Total three-stage oesophagectomy for cancer of the oesophagus. Br J Surg 1976;63:259-62.

78 Skinner DB, Ferguson MK, Soriano A, Little AG, Stasvak VM. Selection of operation for esophageal cancer based on staging. Ann Surg 1986;204:391-401.

79 Matthews HR, Walker SJ. Oesophageal carcinoma: the view from East Birmingham. J R Coll Surg Edinb 1990;35: $279-83$.

80 Belsey RHR. In discussion of paper by Orringer MB, Sloan H. Esophagectomy without thoracotomy. J Thorac Cardiothorac Surg 1978;76:643-54.

81 Wong J. Transhiatal oesophagectomy for carcinoma of the thoracic oesophagus. Br J Surg 1986;73:89-90.

82 Earlam R, Cunha-Melo JR. Oesophageal squamous cell carcinoma. 1. A critical review of surgery. $\mathrm{Br} J$ Surg 1980;67:381-90.

83 Matthews HR, Powell DJ, McKonkey CC. The effect of surgical experience on the results of resection in oesophageal carcinoma. Br J Surg 1986;73:621-3.

84 Couraud L, Hafez-Alqudah A, Clerc P, Meriot S. In Jamieson GG, ed. Surgery of the oesophagus. London: Churchill-Livingstone, 1988:182.

85 Dark JF, Mousalli H, Vaughan R. Surgical treatment of carcinoma of the oesophagus. Thorax 1981;36:891-5.

86 Griffith JL, Davis JT. A twenty year experience with the surgical management of carcinoma of the oesophagus and
gastric cardia. $J$ Thorac Cardiovasc Surg 1980;79:447-52.

87 Jackson JW, Cooper DKC, Guvendick L, Reece-Smith H. Surgical management of malignant tumours of oesophagus and cardia. Br J Surg 1979;66:98-104.

88 Lea R. In: Hurt RL, ed. Management of oesophageal carcinoma. London: Springer, 1989:157-86.

89 McKeown KC. The surgical treatment of carcinoma of the oesophagus. J R Coll Surg Edinb 1985;30:1-14.

90 Akiyama $\mathrm{H}$. Principles of surgical treatment for carcinoma of the esophagus. Ann Surg 1981;194:438-46. 